OPEN ACCESS

Edited by:

Huanbin Zhou,

Institute of Plant Protection (CAAS),

China

Reviewed by:

Yanpeng Wang,

Institute of Genetics and

Developmental Biology (CAS), China

Yiping Qi,

University of Maryland, United States

*Correspondence:

Jose R. Botella

j.botella@uq.edu.au

tThese authors have contributed equally to this work and share first authorship

Specialty section: This article was submitted to Genome Editing in Plants, a section of the journal

Frontiers in Genome Editing

Received: 17 November 2021 Accepted: 02 December 2021

Published: 15 December 2021

Citation:

Gong Z, Cheng $M$ and Botella JR (2021) Non-GM Genome Editing Approaches in Crops.

Front.Genome Ed. 3:817279. doi: 10.3389/fgeed.2021.817279

\section{Non-GM Genome Editing Approaches in Crops}

\author{
Zheng Gong ${ }^{\dagger}$, Ming Cheng ${ }^{\dagger}$ and Jose R. Botella* \\ Plant Genetic Engineering Laboratory, School of Agriculture and Food Science, The University of Queensland, Brisbane, QLD, \\ Australia
}

CRISPR/Cas-based genome editing technologies have the potential to fast-track largescale crop breeding programs. However, the rigid cell wall limits the delivery of CRISPR/ Cas components into plant cells, decreasing genome editing efficiency. Established methods, such as Agrobacterium tumefaciens-mediated or biolistic transformation have been used to integrate genetic cassettes containing CRISPR components into the plant genome. Although efficient, these methods pose several problems, including 1) The transformation process requires laborious and time-consuming tissue culture and regeneration steps; 2) many crop species and elite varieties are recalcitrant to transformation; 3) The segregation of transgenes in vegetatively propagated or highly heterozygous crops, such as pineapple, is either difficult or impossible; and 4) The production of a genetically modified first generation can lead to public controversy and onerous government regulations. The development of transgene-free genome editing technologies can address many problems associated with transgenic-based approaches. Transgene-free genome editing have been achieved through the delivery of preassembled CRISPR/Cas ribonucleoproteins, although its application is limited. The use of viral vectors for delivery of CRISPR/Cas components has recently emerged as a powerful alternative but it requires further exploration. In this review, we discuss the different strategies, principles, applications, and future directions of transgene-free genome editing methods.

Keywords: transgene-free, genome editing, virus induced genome editing, CRISPR (clustered regularly interspaced short palindromic repeat)/Cas9 (CRISPR associated protein 9)-mediated genome editing, non-GM approach, crops, RNPs

\section{INTRODUCTION}

Plant breeding aims to produce improved crop varieties with enhanced agronomic traits and better nutrition qualities for a growing human population. However, traditional breeding methods are often slow, and the production of new traits is restricted by the species' existing genetic variation pool (Voytas and Gao, 2014; Baltes et al., 2017; Mao et al., 2019; Wang et al., 2019; Nasti and Voytas, 2021).

Genome editing allow plant breeders to manipulate crop genomes at the nucleotide level with high precision. In particular, the advent of prokaryotic-derived Clustered Regularly Interspaced Short Palindromic Repeats (CRISPR)/CRISPR associated protein (Cas) systems and its use in plant genome editing has been a crucial turning point towards a new era of crop breeding. Cas9 and Cas12a, are two popular RNA guided engineered nucleases (RGENs) which mediate genome editing, directed by the sequence-specific pairing of a guide RNA (gRNA) to the target DNA (Jinek et al., 2012). CRISPR/Cas systems have been widely adopted for a variety of applications, including gene disruption by the production of insertion-deletion mutations (indels) (Mao et al., 2013), site-specific sequence 
integration (Čermák et al., 2015; Wang et al., 2017), transcriptional control (Lowder et al., 2015; Pan et al., 2021), and base editing (Zong et al., 2017) among others (Zhan et al., 2021). Precise genome editing tools like CRISPR/Cas gives plant breeders unprecedented control over the breeding process at the molecular level. Combined with our current knowledge and the rapid progress in plant genomics, the versatile CRISPR/Cas systems can efficiently introduce genetic variations into the plant genome for crop improvement.

The efficient introduction of genome editing reagents into plants remains one of the grand challenges for this technology (Zhang et al., 2018; Mao et al., 2019; Yang, 2020). Indeed, the minimal CRISPR/Cas complex, a large Cas protein $(>140 \mathrm{kDa}$ for Cas9 and Cas12a) and gRNA needs to be delivered across the rigid cell wall, into the nucleus of plant cells. Currently, delivery mostly relies on Agrobacterium-mediated or biolistic genetic transformation methods (Baltes et al., 2017). However, the stable integration of transgenes in both methods lead to an array of issues, such as the integration of transgenes at random sites in the plant genome which can disrupt essential genes or result in variable transgene expression (Sun et al., 2016; van Kregten et al., 2016; Liu et al., 2019). In addition, many plant species and elite crop varieties are recalcitrant to genetic transformation and/or plant regeneration (Sun et al., 2016). Removal of transgenes through segregation is also difficult or even impossible in asexually propagated or highly heterozygous crops. Most importantly, many jurisdictions impose heavy regulations on Genetically Modified Organisms (GMOs) which restrict their development, commercialization and use in agriculture (Turnbull et al., 2021). The general public's perception of GMO plants is likewise negative, leading to a shift away from GMO products.

CRISPR/Cas genome editing tools enable precise and traceable modifications that are no different from naturally occurring genetic variations selected during conventional breeding (Voytas and Gao, 2014; Pacher and Puchta, 2017; Zhang et al., 2018). Many countries such as the USA, Japan and Australia exclude some or all kinds of genome-edited crops from GMO regulation if they are free of transgenes or foreign DNA (Pacher and Puchta, 2017; Tsuda et al., 2019; Entine et al., 2021). Even the European Union, which regulates all gene-edited plants as GMOs, released a study that recognized its regulations as "not fit for purpose for some new genomics techniques” (European Commission, 2021). Thus, plant genome editing approaches that avoid transgenesis have recently gained considerable attention. Protocols using Cas9 ribonucleoproteins or transient gene expression with viral vectors have emerged as promising tools for genome editing, whilst avoiding foreign DNA integration. These methods do not involve GM and are collectively named as transgene-free genome editing. Here, we will briefly discuss major advances in transgene-free plant genome editing.

\section{RIBONUCLEOPROTEINS}

The direct use of CRISPR/Cas ribonucleoproteins (RNPs) is the most obvious approach to achieve transgene-free genome editing. RNPs can be easily assembled by combining purified Cas protein and in vitro transcribed or chemically synthesized gRNA before being introduced into cells using chemical or physical delivery methods (Figure 1). As such, the use of RNPs circumvents the design and multi-step construction of recombinant vectors, as well as promoter and codon optimisation issues. Most importantly, the CRISPR/Cas RNPs are only transiently present in plant cells prior to degradation by proteases and nucleases (Woo et al., 2015; Zhang et al., 2016; Liang et al., 2017; Banakar et al., 2019). This significantly reduces mosaicism and off-target effects caused by extended exposure of genomic DNA to CRISPR reagents in the conventional DNA delivery systems (Woo et al., 2015; Zhang et al., 2016). The use of RNPs completely avoids transgenesis and should not fall under regulatory oversight (Wolter and Puchta, 2017). Furthermore, RNPs mediate genome editing shortly after cell transfection, as gene transcription and translation is not necessary, enabling the development of approaches for rapid evaluation of multiple CRISPR/Cas systems efficiency in plant tissues (Banakar et al., 2020; Kim et al., 2020).

\subsection{Protoplast Transformation}

The use of CRISPR/Cas9 RNPs was first reported in 2014, for human cell mutagenesis (Kim et al., 2014), and have since been extensively adopted for plant genome editing in a variety of plant species including Arabidopsis thaliana, rice, lettuce, tobacco (Woo et al., 2015; Kim et al., 2017), petunia (Subburaj et al., 2016; Yu et al., 2021), grapevine, apple (Malnoy et al., 2016), maize (Svitashev et al., 2016), wheat (Liang et al., 2017; Liang et al., 2018), soybean (Kim et al., 2017), potato (Andersson et al., 2018; González et al., 2020; Nicolia et al., 2021b), cabbage (Murovec et al., 2018; Park et al., 2019; Lee et al., 2020), banana (Wu et al., 2020), pepper (Kim et al., 2020), witloof (De Bruyn et al., 2020), carrot (Klimek-Chodacka et al., 2021), and tomato (Nicolia et al., 2021a). In most cases, polyethylene glycol-calcium (PEG-Ca $\left.{ }^{2+}\right)$-mediated cell transfection was the method used to deliver the RNPs into plant protoplasts. However, PEG-mediated transformation may cause cell cytotoxicity leading to limited reproducibility. Surprisingly, Andersson et al. (2018) reported that a large proportion of the regenerated plants contained inserts at the target site, containing either random fragments of potato chromosomal DNA or originating from the DNA template used to synthesize the gRNA. Despite the success of PEG-mediated delivery of RNPs in certain transformation-recalcitrant species, few plant species have been satisfactorily regenerated from protoplasts (Yue et al., 2021). Moreover, genome instability caused by protoplast regeneration is not infrequent (Fossi et al., 2019). Due to a lack of well-established and species-specific protoplast isolation and regeneration techniques, especially for monocotyledonous plants, the adoption of PEG-mediated RNP genome editing has been limited thus far (Yue et al., 2021). Other useful strategies for the delivery of genes or proteins to mammalian cells, such as electroporation and lipofection, have also been tested in plants. Electroporation of Chlamydomonas Reinhardtii cells with CRISPR/Cas9 RNPs resulted in approximately $1 \%$ editing efficiency (Baek et al., 2016). Electro-transfection of CRISPR/ Cas9 RNPs into cabbage protoplasts provided a $1.6 \%$ increase in editing efficiency compared to PEG-mediated transfection (Lee 


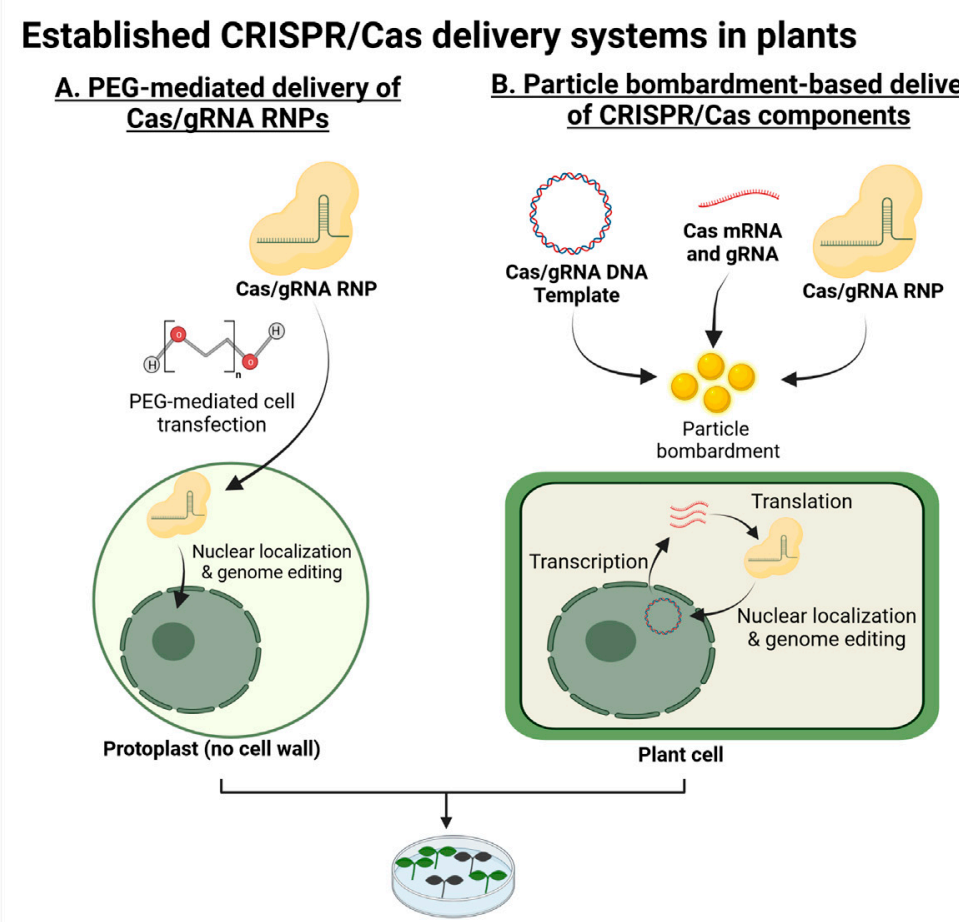

Regeneration of transgene-free, gene edited plants

\section{Delivery systems}

C. Nanoparticles

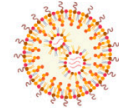

Liposomes (>90 nm)

$\because \%$

Silica NPs (2 -50 nm)

Metalic NPs $(1-40 \mathrm{~nm})$

Dendrimer $(10-20 \mathrm{~nm})$

․․․

Carbon nanotubes $(>1 \mathrm{~nm})$

\section{Meristematic} microinjection

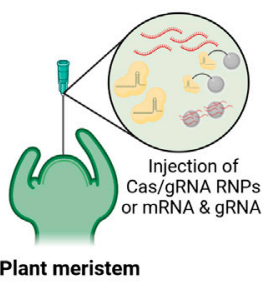

\section{Plant cell types or organs}

\section{E. Gene editing in plant zygotes}
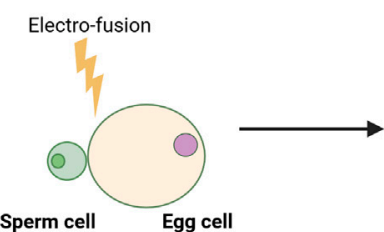

PEG-mediated

Sperm cell

Egg cell
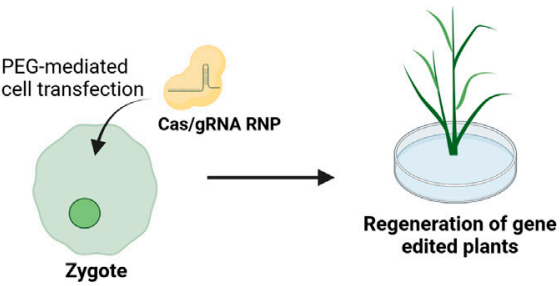

F. Pollen magnetofection ${ }^{\star}$
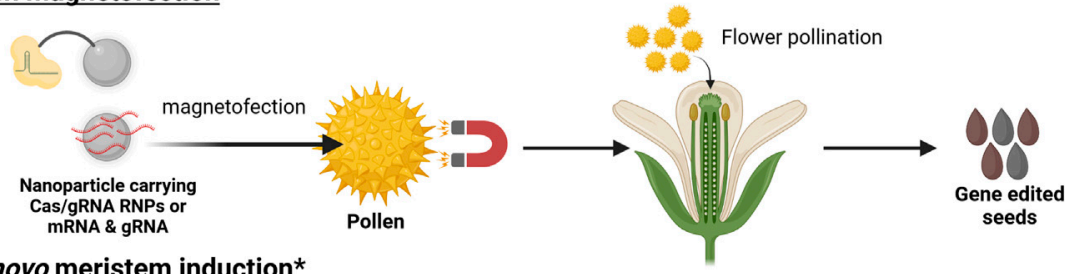

G. De novo meristem induction*

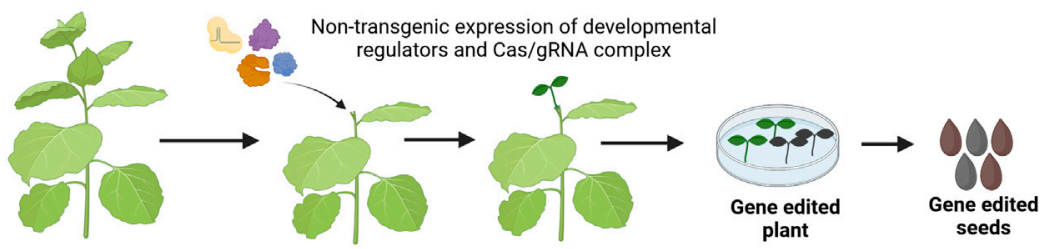

FIGURE 1 | Methods with potential for transgene-free genome editing in plants using in vitro/chemically synthesized Cas mRNA and gRNA, DNA templates or Cas/ gRNA ribonucleoproteins (RNPs) (Created with BioRender.com). The asterisk (*) indicates methods which have not been experimentally tested. (A,B) Established, GMfree systems for the delivery of CRISPR/Cas/gRNA into plants. (A) Polyethylene glycol (PEG)-mediated delivery of preassembled Cas/gRNA RNPs into plant protoplasts. PEG mediates the uptake of Cas/gRNA RNPs into protoplast cells. The Cas/gRNA complex enters the nucleus and induces genome editing. The protoplasts are then regenerated to produce transgene-free gene edited plants. (B) Particle bombardment-based delivery of preassembled Cas/gRNA RNPs, Cas mRNA plus gRNA or Cas/gRNA DNA expression cassettes. The CRISPR components are loaded onto particles and introduced into plant cells using a gene gun or biolistic device. The Cas/ gRNA complexes are localized to the nucleus and induce genome editing. Regeneration from bombarded plant tissue without selection produces gene edited plants 
FIGURE 1 | whilst avoiding transgenesis (in a large proportion of the regenerated plants). (C,D) Potential delivery systems for the application of transgene-free genome editing in plants. (C) Common types of nanoparticles currently used in biotechnology. Nanoparticles, such as carbon nanotubes, have been explored as delivery systems for DNA/RNA and protein into mesophyll through stomata pores (around $10 \mathrm{~nm}$ ). Other nanoparticles, larger than $10 \mathrm{~nm}$, can be introduced into plants by chemical, or physical methods. Therefore, nanoparticles could act as a carrier for the delivery of genome editing reagents into plant cells. Note that nanoparticles are not restricted to spherical forms. (D) Plant meristematic microinjection using phytoinjectors. Phytoinjectors could potentially be adopted for the injection of Cas mRNA and gRNA, RNPs or nanoparticle-bound genome editing reagents. (E-G) Potential target cell types and organs for transgene-free genome editing. (E) Gene editing in plant zygotes. The isolated sperm and egg cells are electro-fused to form zygotes. Early zygotes lack cell walls and the Cas/gRNA RNPs are transfected with PEG. Zygotes are then regenerated to obtain gene edited plants. (F) Gene editing using pollen. Nanoparticles carrying Cas mRNA and gRNAs or Cas/gRNA RNPs could be transfected into pollen through magnetofection. The transfected pollen is used to pollinate a flower to produce transgene-free gene edited seeds. (G) Non-transgenic delivery/transient expression of developmental regulators and CRISPR/Cas reagents in plant organs may produce gene edited, de novo meristems which can be cultured to obtain gene edited seeds.

et al., 2020). Lipofection was demonstrated to transport RNPs into negatively charged tobacco BY2 protoplasts by mixing the CRISPR/Cas9 RNPs with positively charged cationic lipids, resulting in a $6 \%$ editing efficiency (Liu et al., 2020).

\subsection{Particle Bombardment}

Particle bombardment can be used to deliver CRISPR/Cas RNPs into multiple tissues such as immature embryos, leaf discs and calli and is not limited by plant-host range (Altpeter et al., 2005). Major cereal crops, such as rice (Banakar et al., 2020), wheat (Liang et al., 2017; Liang et al., 2019), Brassica (Murovec et al., 2018) and maize (Svitashev et al., 2016) have been successfully edited by bombardment with $0.6 \mu \mathrm{m}$ gold particles coated with CRISPR/Cas RNPs using a helium gene gun. Mutated plants were generated from bombarded embryogenic wheat calli in 6-8 weeks without selection (Liang et al., 2017). In general, the mutagenesis efficiency using particle bombardment of CRISPR/Cas RNPs is modest or low, requiring large-scale mutant screening (Banakar et al., 2019). The addition of a selectable marker plasmid increases the editing efficiency of CRISPR/Cas RNPs, but this approach can result in DNA integration into the plant genome (Svitashev et al., 2016; Banakar et al., 2019). Biolistic bombardment may also result in genome damage, which could lead to phenotypic changes or reduced fitness (Liu et al., 2019).

\subsection{Future Directions}

\subsubsection{Zygotes and Pollen as Delivery Targets}

Other plant material, such as zygotes and pollen have the potential to avoid protoplast regeneration. Rice zygotes are created by uniting isolated egg and sperm cells, a process known as gamete fusion. Cell walls are immature during the early stages of gamete fusion, allowing Toda et al. (2019) to perform PEG-mediated transfection of preassembled CRISPR/ Cas9 RNPs. After 30-40 days of culture, $14-64 \%$ of the generated plants from the zygotes contained CRISPR-induced mutations (Toda et al., 2019). This approach is promising and could be applied to other species with available gamete fusion and regeneration protocols. Pollen manipulation could also circumvent many of the tissue culture and regeneration problems. Pollen grains in many plant species are permeable through apertures of $5-10 \mu \mathrm{m}$ in diameter and thus are theoretically amenable to the delivery of preassembled RNPs using nanotechnological approaches and are discussed in the next section (Zhao et al., 2017).

\subsubsection{Nanoparticles for Cargo Delivery}

Nanoparticles $(<100 \mathrm{~nm})$ have been successfully used to deliver DNA, RNA and proteins into plant cells (Martin-Ortigosa et al., 2013; Zhao et al., 2017; Demirer et al., 2019; Demirer et al., 2020). Polyethyleneimine (PEI)-coated $\mathrm{Fe}_{3} \mathrm{O}_{4}$ magnetic nanoparticles were used to carry exogenous DNA plasmids into the pollen grains of several dicot plants, including cotton, pepper, pumpkin and cocozelle (Zhao et al., 2017). The DNA-loaded nanoparticles were combined with pollen in solution and subjected to a magnetic field to enhance the movement of the particles to the bottom of the recipient and into the pollen grains in a process known as magnetofection (Zhao et al., 2017). Artificial pollination using magnetofected pollen produced genetically modified seeds (Zhao et al., 2017). This approach could theoretically be used to introduce preassembled RNPs into pollen instead of DNA but unfortunately attempts to use magnetofection by several research groups have failed, casting some doubts about the efficiency of the method (Vejlupkova et al., 2020).

In mammalian cells, nanoparticle delivery of CRISPR/Cas9 RNPs have been accomplished (Lee et al., 2017), however no nanomaterial-mediated transgene-free CRISPR/Cas genome editing has been reported in plants so far (Ranjan et al., 2017; Sanzari et al., 2019; Demirer et al., 2021). The use of conjugated nanomaterials/RNPs as delivery method and subsequent release methods by enzymatic or light-mediated cleavage is an attractive possibility for future research (Ahmar et al., 2021; Demirer et al., 2021; Nadakuduti and Enciso-Rodríguez, 2021; Wang et al., 2021).

\section{VIRUS INDUCED GENOME EDITING}

Viral vectors are an efficient tool for gene expression in plants (Scholthof et al., 1996) and have been extensively used for foreign and endogenous gene expression as well as targeted gene silencing (Brisson et al., 1984; French et al., 1986; Chapman et al., 1992; Lu, 2003; Giritch et al., 2006; Gao et al., 2013; Torti et al., 2021). The use of viruses offers multiple advantages including 1) Transient and systemic gene expression without the need for transgenesis (Ellison et al., 2021); 2) high gene expression levels (Pogue and Holzberg, 2012); and 3) the availability of a broad range of viruses that can be engineered for gene expression infecting different plant species (Supplementary Table S1 and Supplementary Table S2). Thus, 


\section{A VIGE through sgRNA Expression}

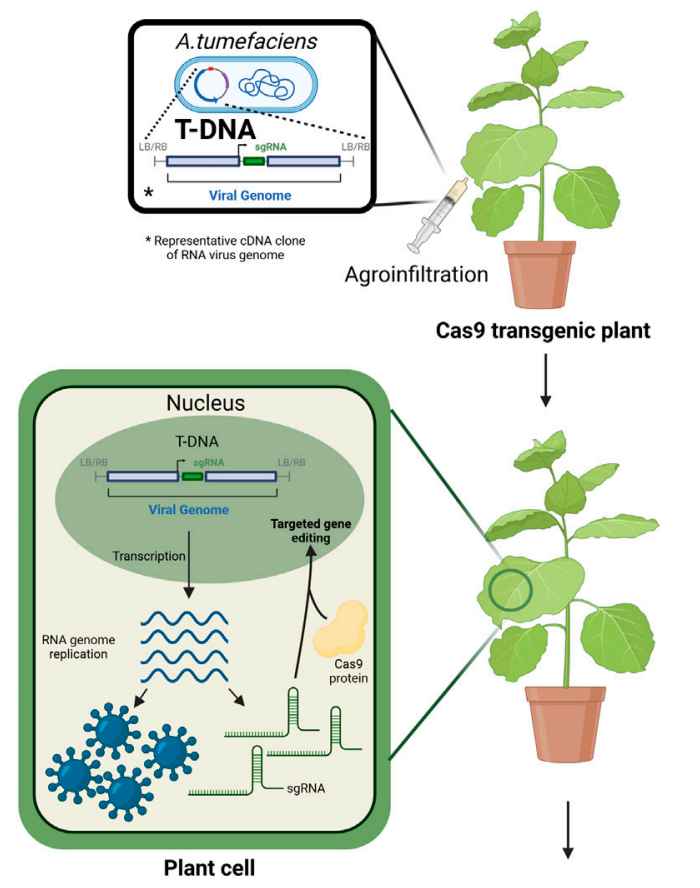

B

Transgene-free VIGE

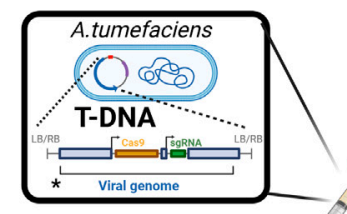

Agroinfiltration
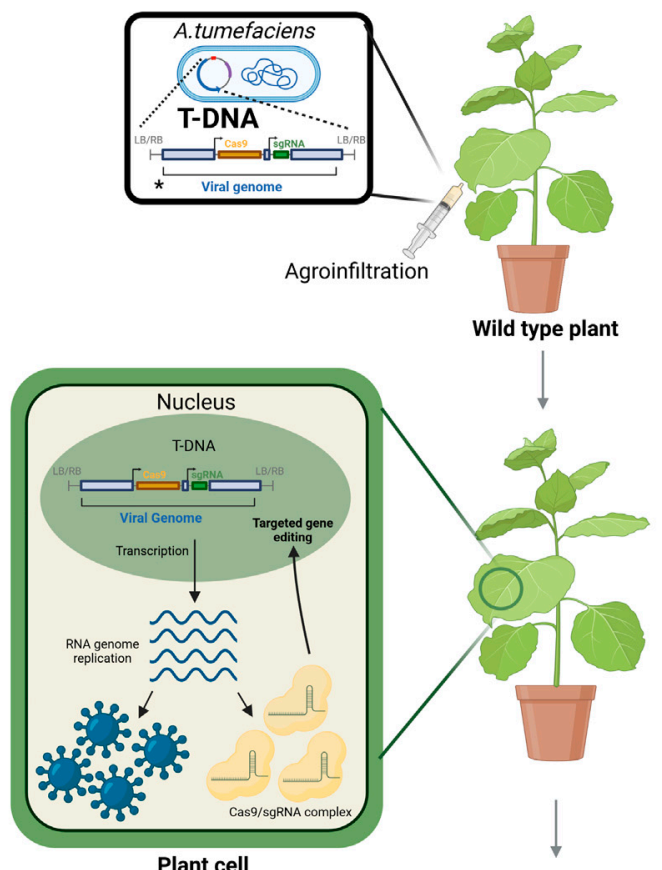

Plant cell

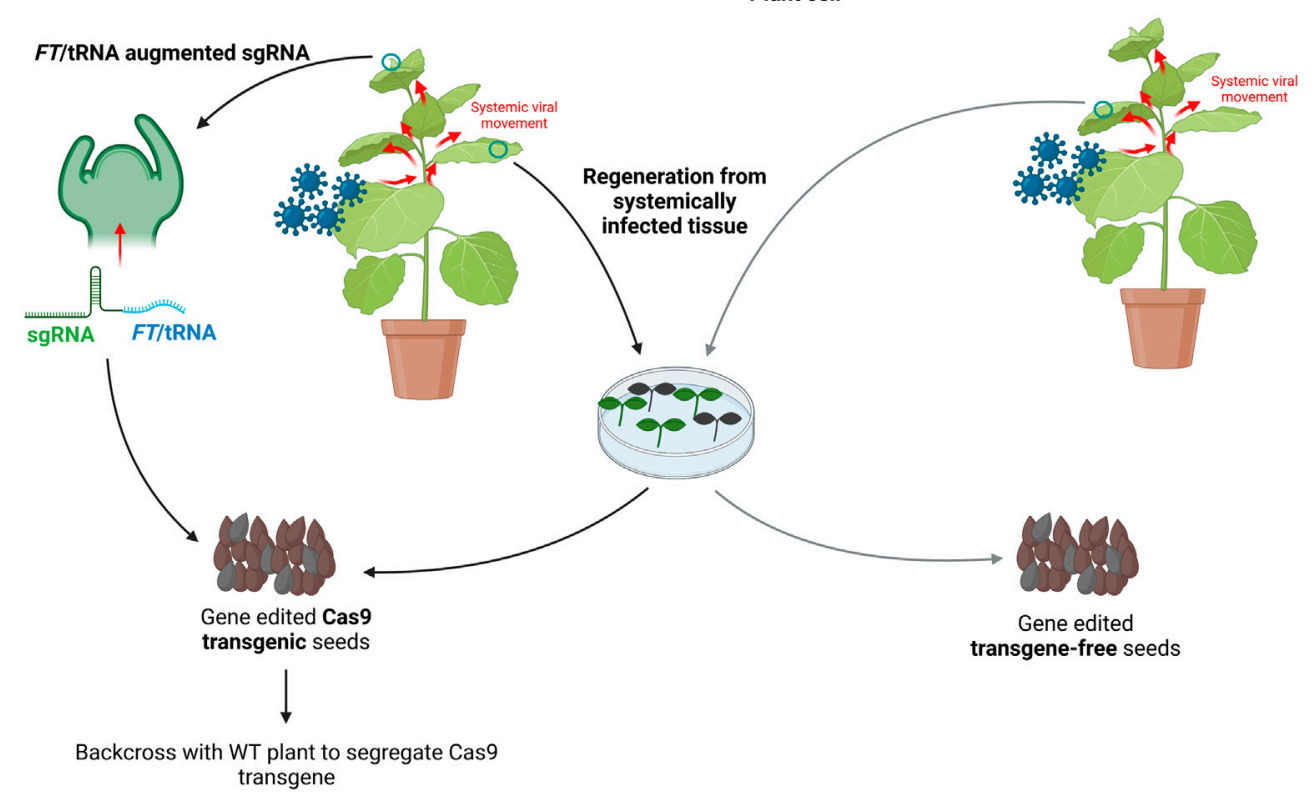

FIGURE 2 | Virus induced genome editing (VIGE) systems in plants (Created with BioRender.com). (A) VIGE through gRNA expression. The gRNA is cloned into the complementary DNA (CDNA) of an RNA virus genome in a binary vector. A. tumefaciens carrying the binary vector with the recombinant viral cDNA is agroinfiltrated into a leaf on Cas9 transgenic plants. The viral cDNA is expressed to produce viral RNA which self-replicates. gRNAs transcribed from the viral vector are bound by the Cas9 protein expressed from the plant integrated transgene. The Cas9/gRNA complex is localized in the nucleus where it induces targeted gene editing. Viral genomes are encapsidated into recombinant virions which exit the plant cell inducing systemic infection. When gRNAs are fused to $F T$ or tRNAs, the augmented gRNA may travel and enter meristematic cells. Gene editing in meristematic cells can produce edited Cas9 transgenic seeds. Alternatively, systemically infected leaf tissue can be used for plant regeneration. Genome edited Cas9 transgenic seeds are obtained from regenerated plants. The gene edited transgenic Cas9 progenies can be backcrossed with wild type (WT) plants to segregate the Cas9 transgene. (B) Transgene-free VIGE system. Certain viruses are capable of carrying and expressing cassettes containing Cas9 and gRNAs. The Cas9 gene and gRNA are introduced into the viral genome cDNA in a binary vector and agroinfiltrated into WT plants. The viral cDNA is expressed to produce viral RNA which self-replicates. Cas9 protein and gRNA are transiently expressed from the viral genome to form a complex. The Cas9/gRNA complex is localized to the nucleus for targeted genome editing. Viral genomes are encapsidated into recombinant virions exiting the plant cell and induces systemic infection. Systemically infected leaf tissue can be used for plant regeneration. The regenerated plants produce transgene-free gene-edited seeds. 
viruses provide an attractive platform for transgene-free delivery of genome editing reagents, providing a promising solution to the delivery bottleneck. In this section, we explore the recent advances in virus induced genome editing (VIGE) (Figure 2). Strategies to insert foreign genes, such as genome editing tools, into viral genomes are well established for many plant viruses (Scholthof et al., 1996; Mortimer et al., 2015) (Supplementary Table S2). The gene-ofinterest is inserted into viral genomes, sometimes replacing nonessential viral genes (Chapman et al., 1992). Infection with recombinant viral genomes into plant tissues is predominantly achieved through agroinfiltration (Marillonnet et al., 2004; Marillonnet et al., 2005). Alternatively, infection can be accomplished by mechanical inoculation of the viral genome or the use of previously infected tissue (Takamatsu et al., 1987). Once inside a cell, the viral genome undergoes its replication lifecycle, inducing local gene expression in the inoculated area before producing complete virions and colonising the plant (Lico et al., 2008; Mortimer et al., 2015). Concurrently, the inserted gene-ofinterest is expressed systemically alongside the viral infection. Transgene-free expression of foreign genes, such as genome editing reagents, can be achieved if genome integration is not involved in the viral lifecycle.

\subsection{Genome Editing Using Positive-Strand RNA Viruses}

RNA viruses have a strong potential for transgene-free genome editing as they multiply through RNA replication and are not usually reverse transcribed into DNA throughout their lifecycle (Ellison et al., 2021).

\subsubsection{Delivery of Zinc Finger Nucleases and Meganucleases}

Tobacco rattle virus (TRV) is a bipartite positive-strand RNA virus (PSV) infecting many dicotyledonous plant species (MacFarlane, 2008; Marton et al., 2010; Ali et al., 2015a). TRV has been modified to express a zinc finger nuclease (ZFN), targeting a loss-of-function GUS transgene in Nicotiana benthamiana and Petunia hybrida transgenic lines (Marton et al., 2010). Zinc finger nucleasemediated editing of GUS restored GUS activity producing a visible phenotype upon staining in systemic leaves. In addition, TRV infected tissues from these experiments were used for regeneration. Virus-free and zinc finger nuclease-free seedlings containing edits in the GUS gene were identified from T0 seeds of the regenerated plants (Marton et al., 2010). TRV was also used to express a meganuclease targeting DIHYDROFLAVONOL 4REDUCTASE (DFR) in Nicotiana alata (Honig et al., 2015). DFR is involved in the synthesis of anthocyanins, simplifying the visual identification of mutations by the presence of reduced pigmentation in the N. alata purple petals. Analysis of the progeny of three infected plants revealed the presence of two plants containing mutations in one of the two DFR genes present in the genome (Honig et al., 2015).

\subsubsection{Delivery of CRISPR/Cas gRNAs}

In contrast with zinc finger nucleases and meganucleases, the delivery of CRISPR/Cas reagents with PSVs is notably more difficult. The size of the Cas9 coding region $(>4 \mathrm{~kb})$, significantly larger than ZFNs $(\sim 1,2 \mathrm{~kb})$, create problems for delivery using PSVs due to their limited cargo size. Large insertions also cause genome instability from selective pressure towards viral particles lacking the insert (Walker et al., 2015; Kujur et al., 2021; Tsanova et al., 2021). Initial studies overcame the size problem by using the PSV system to express small gRNAs into transgenic plant lines constitutively expressing Cas9 as a proof-of-concept. PSVs such as TRV, Beet necrotic yellow vein virus (BNYVV), Potato virus X (PVX) and the legume-infecting, Pea early browning virus (PEBV) have been used to express gRNAs in Cas9-positive N. benthamiana lines (Ali et al., 2015a; Ali et al., 2015b; Ali et al., 2018; Jiang et al., 2019; Uranga et al., 2021a). Efficient VIGE was detected in systemically infected leaves with the four PSVs, ranging from $\sim 30$ to $\sim 85 \%$ editing efficiency. Furthermore, when PVX infected tissues were used for regeneration of plants by tissue culture, edited seedlings were recovered (Uranga et al., 2021a). It is to note that gRNA delivery and highly efficient gene editing in Cas9 transgenic $N$. benthamiana was also achieved with a DNA virus, Cabbage leaf curl virus (Yin et al., 2015).

For monocotyledonous plants, the tripartite PSV, barley stripe mosaic virus (BSMV) was used to express gRNAs targeting endogenous genes in the agriculturally important crops, wheat and maize using a similar approach to the ones mentioned above (Hu et al., 2019). BSMV showed very high editing efficiency in systemic leaves of Cas9 transgenic wheat ( 62-78\%) and maize $(\sim 48 \%)$ lines. Expression of gRNAs using the foxtail mosaic virus (FoMV) mediated efficient VIGE in Cas9 transgenic Setaria viridis ( $60 \%$ in systemic leaves) but efficiency significantly dropped in Cas9 transgenic maize ( 3-6\%) (Mei et al., 2019). In both VIGE systems, wheat, maize and $S$. viridis plants were easily infected by rub-inoculation with $N$. benthamiana leaves from plants previously infected by agroinfiltration ( $\mathrm{Hu}$ et al., 2019; Mei et al., 2019). The possibility of efficient trans-species rub-inoculation is especially important for monocots where the introduction of viral genomes into mature plants is difficult, demonstrating the versatility of viral vectors.

Despite the high editing efficiency demonstrated by the abovementioned PSV vectors in systemic tissues, an important consideration is whether this approach produces gene edits in the progeny of infected plants. Unfortunately, these studies either 1) failed to obtain gene edits in the progeny (FoMV infected $S$. viridis), 2) obtained an extremely low frequency $(2 / 1,320$ seedlings from TRV infected $N$. benthamiana) or 3) heritability was not determined (BNYVV, PEBV and BSMV infected $N$. benthamiana, FoMV infected maize).

\subsubsection{Heritable Genome Editing Through gRNA Augmentation}

To optimize heritable VIGE in CRISPR/Cas systems, Ellison et al. (2020) fused the A. thaliana FLOWERING LOCUS T (FT) mRNA to the 3' end of the gRNA in an approach called gRNA augmentation. Substantial evidence suggests that the FT mRNA moves systemically in the plant and enters the meristem to induce flowering (Li et al., 2009; Li et al., 2011). The idea behind gRNA augmentation is that the addition of FT or 
other mobility sequences such as tRNAs to the gRNA will confer systemic mobility and access to meristematic cells to produce heritable editing. When transgenic $N$. benthamiana plants overexpressing Cas9 were infected with TRV vectors containing FT augmented gRNAs, up to $65 \%$ of the progeny contained CRISPR-generated mutations (Ellison et al., 2020). Since the initial report, gRNA FT augmentation has been used with other dicotyledon viruses such as PVX and a DNA virus, Cotton leaf crumple virus, generating heritable edits of $22 \%$ in $N$. benthamiana and $>4 \%$ in A. thaliana seedlings, respectively (Lei et al., 2021; Uranga et al., 2021a). This strategy has also been implemented in monocot crops such as wheat with surprising results. Cas9 transgenic wheat lines were infected with BSMV expressing either unaugmented gRNAs or augmented gRNAs with wheat FT (Li et al., 2021). Unexpectedly, gene edits were present in almost all M1 progeny from plants infected with unaugmented gRNA whereas, the progeny of plants infected with BSMV-FT augmented gRNA were rarely edited. To quickly remove the Cas9 transgene, the authors used anthers from plants infected with BSMV-gRNA for pollination of wild type plants. The progeny was self-pollinated to obtain edited plants lacking the Cas9 transgene (Li et al., 2021). This BSMV VIGE system has the potential to circumvent the need for tissue culture in genome editing pipelines involving monocots such as maize and barley which BSMV infects.

\subsubsection{Transgene-Free Genome Editing Using Positive-Strand RNA Virus}

Despite achieving high gene editing efficiency and sometimes heritable editing, the above discussed approaches are not truly transgene-free as they need to use a Cas9 expressing line as starting plant material for infection. PVX is a monopartite PSV with a filamentous flexible architecture which may allow to incorporate the large Cas9 gene into its RNA genome (Ariga et al., 2020). Recently, PVX was used to transiently express Cas9 and gRNA in N. benthamiana. No systemic editing was discussed in this work, suggesting that none was found possibly because the incorporation of the large Cas9 cassette led to defective viral movement. Nevertheless, regeneration of plants from tissues agroinfiltrated with the viral cDNA yielded $>50 \%$ plants containing mutations with $18 \%$ also containing a T-DNA integration. The same strategy was attempted using a nickase Cas9-base editor fusion with $>60 \%$ of regenerated plants containing base edits while $\sim 30 \%$ contained T-DNA integration (Ariga et al., 2020). The progeny from regenerated plants retained genomic edits but were free of PVX RNA. To avoid T-DNA integration, the authors performed agroinfiltration to establish infection in a source plant and used mechanical inoculation from the source plant into recipient plants. In this way, the recipient plants were never in contact with Agrobacterium, eliminating the risk of T-DNA incorporation, thus providing a DNA free method for editing. Unfortunately, this approach proved much less efficient than the direct agroinfiltration with only $2-4 \%$ of regenerated pants containing mutations. A non-systemic PSV expression vector based on the tobacco mosaic virus was also developed which expressed both Cas 9 and gRNA for gene editing in the presence of p19, a viral suppressor of RNA silencing. However, no attempt was made to regenerate gene edited plants (Chiong et al., 2021).

Foxtail mosaic virus (FoMV), from the same Potexvirus genus as PVX, has been used to mediate systemic gene editing in a transgene-free fashion (Zhang et al., 2020). N. benthamiana leaves were simultaneously agroinfiltrated with a FoMV vector containing a Cas9 expression cassette and a second FoMV vector containing a gRNA cassette targeting the PHYTOENE DESATURASE (PDS) gene. Sequencing of the targeted genomic region detected no edits but addition of a cassette containing the viral RNA silencing suppressor, $p 19$, to the gRNA vector produced gene editing in systemic tissues (Zhang et al., 2020). These results are in line with recent research indicating that RNA silencing suppressors can increase genome editing efficiency (Mao et al., 2018; Zhang et al., 2020; Chiong et al., 2021; Mao et al., 2021). Unfortunately, the authors did not attempt to regenerate plants from systemically infected tissue or test heritable editing in the progeny of infected plants and previous studies have failed to obtain edited seeds (Zhang et al., 2020).

Similarly, Uranga et al. (2021b) achieved transgene-free genome editing using two compatible viruses that can co-infect the same cells. The PSV, Tobacco etch virus (TEV) was used to express CRISPR/Cas12a by replacing the NIb gene in the TEV genome. Another PVX virus expressing both the gRNA and the NIb gene to supplement the recombinant TEV was constructed. Both recombinant viral genomes were co-agroinfiltrated into wild type N. benthamiana, mediating around $20 \%$ gene editing efficiency in systemic leaves. Although the authors did not investigate the heritability of gene editing, we believe that regeneration from systemically infected tissue is likely to produce gene-edited progenies (Uranga et al., 2021b).

\subsection{Genome Editing Using Negative-Strand Viruses}

Rhabdoviruses are a group of negative-strand RNA viruses containing a large genome (>10 kb) (Jackson et al., 2005). Rhabdoviruses have large cargo capacities and high gene stability, making them a suitable candidate for transgene-free genome editing (Walker et al., 2015; Dietzgen et al., 2017). The Barley yellow striate mosaic virus (BYSMV) was the first monocot-infecting rhabdovirus developed into an expression system (Gao et al., 2019). When a BYSMV-based vector was used to express Cas9 and gRNA in $N$. benthamiana plants, Sanger sequencing successfully detected different indels in the infiltrated area, but systemic gene editing was not discussed. The authors also explored the use of BYSMV as a gene expression platform for planthoppers and monocots such as barley, wheat and Setaria italica; however, genome editing was not investigated in these systems (Gao et al., 2019).

The Sonchus yellow net virus (SYNV), a rhabdovirus infecting dicotyledonous species, has been also used to express Cas9 and gRNA in N. benthamiana. SYNV-mediated gene editing generated mutations in systemic tissues with high efficiency for a GFP transgene (77-91\%), as well as three endogenous genes (40-79\% for PDS, 53\%-91\% for RDR6, and 79-91\% for SGS3) (Ma et al., 2020). Up to $93 \%$ of plants regenerated from systemically infected leaves contained some form of gene editing which also produced 
edited seeds in the next generation. Unfortunately, heritable editing was not detected in seeds from the initially infected plants (Ma et al., 2020). Although the host range of SYNV is extremely limited, there are multiple rhabdoviruses infecting a diverse range of plant species, thus, a suite of rhabdovirus expression platforms can be developed for different plant species.

\subsection{Future Directions}

Viruses have the potential to become an efficient and versatile vector for the delivery of CRISPR genome editing reagents, however, several important limitations still need to be addressed, the most important being the large size of Cas9. Although some of the available methods can achieve seed heritability using mobility sequences, they still require the use of transgenic Cas9 lines while transgene-free genome editing using viral vectors involves tissue culture for plant regeneration (Figure 2) (Ellison et al., 2020; Ma et al., 2020; Zhang et al., 2020). It will be interesting to investigate whether heritable editing can be achieved by combining mobility sequences in a rhabdovirus, FoMV or TEV-PVX based VIGE platform (Uranga et al., 2021b). Several recent studies have also discovered new RGENs with dramatically reduced size compared to Cas9 ( 1,000-1,400 amino acids). For example, the phage derived Cas $\Phi$ is a compact RGEN ( 700-800 amino acids) capable of generating gene edits in A. thaliana protoplasts, albeit at low efficiency (Pausch et al., 2020). Obligated mobile element-guided activity (OMEGA) is another class of transposon-encoded RGENs with a reduced size ( $\sim 400$ amino acids) (Altae-Tran et al., 2021). Miniature CRISPR associated RGENs such as Cas12f are also being explored for gene editing capability and engineered for improved efficiency (Bigelyte et al., 2021; Xu et al., 2021). The discovery and optimization of these smaller genome editing tools may facilitate delivery with germline infecting PSVs such as TRV or BSMV.

\section{DISCUSSION}

Transgene-free genome editing can be an ideal technology to breed sustainable and more nutritious crops; however, several plantspecific challenges need to be overcome before it can achieve its full potential. One of the most significant hurdles is the delivery of CRISPR/Cas components into plant cells, whilst avoiding transgenesis. The use of preassembled CRISPR/Cas RNPs is arguably the most direct option, but the available methods utilise specific plant cells or organs such as protoplasts, immature embryos, or zygotes followed by regeneration of whole plants. These processes are technically difficult, inefficient, and are not available for many economically important crops. Viral vectors have also emerged as promising tools for transgene-free genome editing, especially because they can be used in full plants and there is a large

\section{REFERENCES}

Ahmar, S., Mahmood, T., Fiaz, S., Mora-Poblete, F., Shafique, M. S., Chattha, M. S., et al. (2021). Advantage of Nanotechnology-Based Genome Editing System and its Application in Crop Improvement. Front. Plant Sci. 12, 663849. doi:10.3389/ fpls.2021.663849 number of virus vectors for gene silencing which are available to be implemented for VIGE (Supplementary Table S2). Multiple VIGE systems have been developed for transient and systemic expression of Cas9 and/or gRNAs with efficient editing in dicotyledonous and monocotyledonous species (Supplementary Table S1). But efficient heritable mutations were only achieved through plant regeneration. Some viral systems and innovative approaches such as gRNA augmentation with mobility sequences can achieve heritable gene editing through seeds but they still need to use transgenic Cas9 plants. The ideal VIGE system should combine transgene-free and heritability at acceptable efficiency to alleviate the genome editing delivery bottleneck. The use of nanomaterials as delivery systems for plants is only starting but we expect to see rapid advances with this approach. Alternative strategies such as the use of mRNA-based genome editing (Zhang et al., 2016) or the de novo induction of meristems (Maher et al., 2020) have been reported but have not yet being been adopted by the wider research community. Even though steady and continuous progress is being made, the field is in need of completely new approaches and the ideal solution might involve development of new and disruptive technologies.

\section{AUTHOR CONTRIBUTIONS}

ZG and MC have contributed equally to this work and share first authorship. JB, ZG, and MC conceived the idea. ZG and MC wrote the manuscript. All authors contributed to the discussion and revision of the final manuscript.

\section{FUNDING}

ZG is funded by an Australian Government Research Training Program Scholarship. MC is funded by a $\mathrm{PhD}$ scholarship from the University of Queensland supporting an Australian Research Council linkage project.

\section{ACKNOWLEDGMENTS}

We are grateful to Genevieve Durrington for reviewing the abstract and Prof. Wainer Montero-Carmona for reading the entire manuscript.

\section{SUPPLEMENTARY MATERIAL}

The Supplementary Material for this article can be found online at: https://www.frontiersin.org/articles/10.3389/fgeed.2021.817279/ full\#supplementary-material

Ali, Z., Abul-Faraj, A., Li, L., Ghosh, N., Piatek, M., Mahjoub, A., et al. (2015a). Efficient Virus-Mediated Genome Editing in Plants Using the CRISPR/Cas9 System. Mol. Plant 8 (8), 1288-1291. doi:10.1016/ j.molp.2015.02.011

Ali, Z., Abul-Faraj, A., Piatek, M., and Mahfouz, M. M. (2015b). Activity and Specificity of TRV-Mediated Gene Editing in Plants. Plant Signal. Behav. 10 (10), e1044191. doi:10.1080/15592324.2015.1044191 
Ali, Z., Eid, A., Ali, S., and Mahfouz, M. M. (2018). Pea Early-browning VirusMediated Genome Editing via the CRISPR/Cas9 System in Nicotiana Benthamiana and Arabidopsis. Virus. Res. 244, 333-337. doi:10.1016/ j.virusres.2017.10.009

Altae-Tran, H., Kannan, S., Demircioglu, F. E., Oshiro, R., Nety, S. P., McKay, L. J., et al. (2021). The Widespread IS200/IS605 Transposon Family Encodes Diverse Programmable RNA-Guided Endonucleases. Science 374, 57-65. doi:10.1126/ science.abj6856

Altpeter, F., Baisakh, N., Beachy, R., Bock, R., Capell, T., Christou, P., et al. (2005). Particle Bombardment and the Genetic Enhancement of Crops: Myths and Realities. Mol. Breed. 15 (3), 305-327. doi:10.1007/s11032-0048001-y

Andersson, M., Turesson, H., Olsson, N., Fält, A.-S., Ohlsson, P., Gonzalez, M. N., et al. (2018). Genome Editing in Potato via CRISPR-Cas9 Ribonucleoprotein Delivery. Physiol. Plantarum 164 (4), 378-384. doi:10.1111/ppl.12731

Ariga, H., Toki, S., and Ishibashi, K. (2020). Potato Virus X Vector-Mediated DNA-free Genome Editing in Plants. Plant Cel Physiol. 61 (11), 1946-1953. doi:10.1093/pcp/pcaa123

Baek, K., Kim, D. H., Jeong, J., Sim, S. J., Melis, A., Kim, J.-S., et al. (2016). DNAfree Two-Gene Knockout in Chlamydomonas Reinhardtii via CRISPR-Cas9 Ribonucleoproteins. Sci. Rep. 6 (1), 30620. doi:10.1038/srep30620

Baltes, N. J., Gil-Humanes, J., and Voytas, D. F. (2017). Genome Engineering and Agriculture: Opportunities and Challenges. Prog. Mol. Biol. Transl. Sci. 149, 1-26. doi:10.1016/bs.pmbts.2017.03.011

Banakar, R., Eggenberger, A. L., Lee, K., Wright, D. A., Murugan, K., Zarecor, S., et al. (2019). High-frequency Random DNA Insertions upon Co-delivery of CRISPR-Cas9 Ribonucleoprotein and Selectable Marker Plasmid in rice. Sci. Rep. 9 (1), 19902. doi:10.1038/s41598-019-55681-y

Banakar, R., Schubert, M., Collingwood, M., Vakulskas, C., Eggenberger, A. L., and Wang, K. (2020). Comparison of CRISPR-Cas9/Cas12a Ribonucleoprotein Complexes for Genome Editing Efficiency in the Rice Phytoene Desaturase (OsPDS) Gene. Rice 13 (1), 4. doi:10.1186/s12284-019-0365-z

Bigelyte, G., Young, J. K., Karvelis, T., Budre, K., Zedaveinyte, R., Djukanovic, V., et al. (2021). Miniature Type V-F CRISPR-Cas Nucleases Enable Targeted DNA Modification in Cells. Nat. Commun. 12 (1), 6191. doi:10.1038/s41467-02126469-4

Brisson, N., Paszkowski, J., Penswick, J. R., Gronenborn, B., Potrykus, I., and Hohn, T. (1984). Expression of a Bacterial Gene in Plants by Using a Viral Vector. Nature 310 (5977), 511-514. doi:10.1038/310511a0

Čermák, T., Baltes, N. J., Čegan, R., Zhang, Y., and Voytas, D. F. (2015). Highfrequency, Precise Modification of the Tomato Genome. Genome Biol. 16 (1), 232. doi:10.1186/s13059-015-0796-9

Chapman, S., Kavanagh, T., and Baulcombe, D. (1992). Potato Virus X as a Vector for Gene Expression in Plants. Plant J. 2 (4), 549-557. doi:10.1046/j.1365313x.1992.t01-24-00999.x

Chiong, K. T., Cody, W. B., and Scholthof, H. B. (2021). RNA Silencing SuppressorInfluenced Performance of a Virus Vector Delivering Both Guide RNA and Cas9 for CRISPR Gene Editing. Sci. Rep. 11 (1), 6769. doi:10.1038/s41598-02185366-4

De Bruyn, C., Ruttink, T., Eeckhaut, T., Jacobs, T., De Keyser, E., Goossens, A., et al. (2020). Establishment of CRISPR/Cas9 Genome Editing in Witloof (Cichorium Intybus Var. Foliosum). Front. Genome Ed. 2, 604876. doi:10.3389/ fgeed.2020.604876

Demirer, G. S., Silva, T. N., Jackson, C. T., Thomas, J. B., Ehrhardt, D. W., Mortimer, J. C., et al. (2021). Nanotechnology to advance CRISPR-Cas Genetic Engineering of Plants. Nat. Nanotechnol. 16 (3), 243-250. doi:10.1038/s41565021-00854-y

Demirer, G. S., Zhang, H., Goh, N. S., Pinals, R. L., Chang, R., and Landry, M. P. (2020). Carbon Nanocarriers Deliver siRNA to Intact Plant Cells for Efficient Gene Knockdown. Sci. Adv. 6 (26), eaaz0495. doi:10.1126/sciadv.aaz0495

Demirer, G. S., Zhang, H., Matos, J. L., Goh, N. S., Cunningham, F. J., Sung, Y., et al. (2019). High Aspect Ratio Nanomaterials Enable Delivery of Functional Genetic Material without DNA Integration in Mature Plants. Nat. Nanotechnol. 14 (5), 456-464. doi:10.1038/s41565-019-0382-5

Dietzgen, R. G., Kondo, H., Goodin, M. M., Kurath, G., and Vasilakis, N. (2017). The Family Rhabdoviridae: Mono- and Bipartite Negative-Sense RNA Viruses with Diverse Genome Organization and Common Evolutionary Origins. Virus. Res. 227, 158-170. doi:10.1016/j.virusres.2016.10.010
Ellison, E. E., Chamness, J. C., and Voytas, D. F. (2021). "Viruses as Vectors for the Delivery of Gene-Editing Reagents," in Genome Editing for Precision Crop Breeding (Cambridge, UK: Burleigh Dodds Science Publishing), 97-122. doi:10.1201/9781003048237-5

Ellison, E. E., Nagalakshmi, U., Gamo, M. E., Huang, P.-j., Dinesh-Kumar, S., and Voytas, D. F. (2020). Multiplexed Heritable Gene Editing Using RNA Viruses and mobile Single Guide RNAs. Nat. Plants 6 (6), 620-624. doi:10.1038/s41477020-0670-y

Entine, J., Felipe, M. S. S., Groenewald, J.-H., Kershen, D. L., Lema, M., McHughen, A., et al. (2021). Regulatory Approaches for Genome Edited Agricultural Plants in Select Countries and Jurisdictions Around the World. Transgenic Res. 30 (4), 551-584. doi:10.1007/s11248-021-00257-8

European Commission (2021). EC Study on New Genomic Techniques. Online. European Commission. Available at: https://ec.europa.eu/food/plants/ genetically-modified-organisms/new-techniques-biotechnology/ec-study-newgenomic-techniques_en (Accessed November 04, 2021).

Fossi, M., Amundson, K., Kuppu, S., Britt, A., and Comai, L. (2019). Regeneration of Solanum tuberosum Plants from Protoplasts Induces Widespread Genome Instability. Plant Physiol. 180 (1), 78-86. doi:10.1104/pp.18.00906

French, R., Janda, M., and Ahlquist, P. (1986). Bacterial Gene Inserted in an Engineered RNA Virus: Efficient Expression in Monocotyledonous Plant Cells. Science 231 (4743), 1294-1297. doi:10.1126/science.231.4743.1294

Gao, Q., Xu, W. Y., Yan, T., Fang, X. D., Cao, Q., Zhang, Z. J., et al. (2019). Rescue of a Plant Cytorhabdovirus as Versatile Expression Platforms for Planthopper and Cereal Genomic Studies. New Phytol. 223 (4), 2120-2133. doi:10.1111/ nph. 15889

Gao, Y., Xiao, B., and Dewey, R. (2013). Construction of PVX-FT System that Inducing Early Flowering in Tobacco. Acta Tabacaria Sin. 19, 102-105. doi:10.3969/j.issn. 1004-5708.2013.06.016

Giritch, A., Marillonnet, S., Engler, C., Van Eldik, G., Botterman, J., Klimyuk, V., et al. (2006). Rapid High-Yield Expression of Full-Size IgG Antibodies in Plants Coinfected with Noncompeting Viral Vectors. Proc. Natl. Acad. Sci. 103 (40), 14701-14706. doi:10.1073/pnas.0606631103

González, M. N., Massa, G. A., Andersson, M., Turesson, H., Olsson, N., Fält, A.-S., et al. (2020). Reduced Enzymatic Browning in Potato Tubers by Specific Editing of a Polyphenol Oxidase Gene via Ribonucleoprotein Complexes Delivery of the CRISPR/Cas9 System. Front. Plant Sci. 10, 1649. doi:10.3389/ fpls.2019.01649

Honig, A., Marton, I., Rosenthal, M., Smith, J. J., Nicholson, M. G., Jantz, D., et al. (2015). Transient Expression of Virally Delivered Meganuclease in Planta Generates Inherited Genomic Deletions. Mol. Plant 8 (8), 1292-1294. doi:10.1016/j.molp.2015.04.001

Hu, J., Li, S., Li, Z., Li, H., Song, W., Zhao, H., et al. (2019). A Barley Stripe Mosaic Virus-based Guide RNA Delivery System for Targeted Mutagenesis in Wheat and maize. Mol. Plant Pathol. 20 (10), 1463-1474. doi:10.1111/mpp.12849

Jackson, A. O., Dietzgen, R. G., Goodin, M. M., Bragg, J. N., and Deng, M. (2005). Biology of Plant Rhabdoviruses. Annu. Rev. Phytopathol. 43 (1), 623-660. doi:10.1146/annurev.phyto.43.011205.141136

Jiang, N., Zhang, C., Liu, J. Y., Guo, Z. H., Zhang, Z. Y., Han, C. G., et al. (2019). Development of Beet Necrotic Yellow Vein Virus -based Vectors for Multiplegene Expression and Guide RNA Delivery in Plant Genome Editing. Plant Biotechnol. J. 17 (7), 1302-1315. doi:10.1111/pbi.13055

Jinek, M., Chylinski, K., Fonfara, I., Hauer, M., Doudna, J. A., and Charpentier, E. (2012). A Programmable Dual-RNA-Guided DNA Endonuclease in Adaptive Bacterial Immunity. Science 337 (6096), 816-821. doi:10.1126/ science. 1225829

Kim, H., Choi, J., and Won, K.-H. (2020). A Stable DNA-free Screening System for CRISPR/RNPs-mediated Gene Editing in Hot and Sweet Cultivars of Capsicum Annuum. BMC Plant Biol. 20 (1), 449. doi:10.1186/s12870-020-02665-0

Kim, S., Kim, D., Cho, S. W., Kim, J., and Kim, J. S. (2014). Highly Efficient RNAguided Genome Editing in Human Cells via Delivery of Purified Cas9 Ribonucleoproteins. Genome. Res. 24 (6), 1012-1019. doi:10.1101/ gr.171322.113

Kim, H., Kim, S.-T., Ryu, J., Kang, B.-C., Kim, J.-S., and Kim, S.-G. (2017). CRISPR/ Cpf1-mediated DNA-free Plant Genome Editing. Nat. Commun. 8 (1), 14406. doi:10.1038/ncomms 14406

Klimek-Chodacka, M., Gieniec, M., and Baranski, R. (2021). Multiplex SiteDirected Gene Editing Using Polyethylene Glycol-Mediated Delivery of 
CRISPR gRNA:Cas9 Ribonucleoprotein (RNP) Complexes to Carrot Protoplasts. Int. J. Mol. Sci. 22 (19), 10740. doi:10.3390/ijms221910740

Kujur, S., Senthil-Kumar, M., and Kumar, R. (2021). Plant Viral Vectors: Expanding the Possibilities of Precise Gene Editing in Plant Genomes. Plant Cel Rep. 40 (6), 931-934. doi:10.1007/s00299-021-02697-2

Lee, K., Conboy, M., Park, H. M., Jiang, F., Kim, H. J., Dewitt, M. A., et al. (2017). Nanoparticle Delivery of Cas9 Ribonucleoprotein and Donor DNA In Vivo Induces Homology-Directed DNA Repair. Nat. Biomed. Eng. 1 (11), 889-901. doi:10.1038/s41551-017-0137-2

Lee, M. H., Lee, J., Choi, S. A., Kim, Y.-S., Koo, O., Choi, S. H., et al. (2020). Efficient Genome Editing Using CRISPR-Cas9 RNP Delivery into Cabbage Protoplasts via Electro-Transfection. Plant Biotechnol. Rep. 14 (6), 695-702. doi:10.1007/ s11816-020-00645-2

Lei, J., Dai, P., Li, Y., Zhang, W., Zhou, G., Liu, C., et al. (2021). Heritable Gene Editing Using FT Mobile Guide RNAs and DNA Viruses. Plant Methods 17 (1). doi:10.1186/s13007-021-00719-4

Li, C., Gu, M., Shi, N., Zhang, H., Yang, X., Osman, T., et al. (2011). Mobile FT mRNA Contributes to the Systemic Florigen Signalling in floral Induction. Sci. Rep. 1 (1), 73. doi:10.1038/srep00073

Li, C., Zhang, K., Zeng, X., Jackson, S., Zhou, Y., and Hong, Y. (2009). A Cis Element within Flowering Locus $\mathrm{T}$ mRNA Determines its Mobility and Facilitates Trafficking of Heterologous Viral RNA. J. Virol. 83, 3540-3548. doi:10.1128/JVI.02346-08

Li, T., Hu, J., Sun, Y., Li, B., Zhang, D., Li, W., et al. (2021). Highly Efficient Heritable Genome Editing in Wheat Using an RNA Virus and Bypassing Tissue Culture. Mol. Plant 14, 1787-1798. doi:10.1016/j.molp.2021.07.010

Liang, Z., Chen, K., and Gao, C. (2019). Biolistic Delivery of CRISPR/Cas9 with Ribonucleoprotein Complex in Wheat. Methods Mol. Biol. 1917, 327-335. doi:10.1007/978-1-4939-8991-1_24

Liang, Z., Chen, K., Li, T., Zhang, Y., Wang, Y., Zhao, Q., et al. (2017). Efficient DNA-free Genome Editing of Bread Wheat Using CRISPR/Cas9 Ribonucleoprotein Complexes. Nat. Commun. 8 (1), 14261. doi:10.1038/ ncomms14261

Liang, Z., Chen, K., Yan, Y., Zhang, Y., and Gao, C. (2018). Genotyping GenomeEdited Mutations in Plants Using CRISPR Ribonucleoprotein Complexes. Plant Biotechnol. J. 16 (12), 2053-2062. doi:10.1111/pbi.12938

Lico, C., Chen, Q., and Santi, L. (2008). Viral Vectors for Production of Recombinant Proteins in Plants. J. Cel. Physiol. 216 (2), 366-377. doi: $10.1002 /$ jcp. 21423

Liu, J., Nannas, N. J., Fu, F.-F., Shi, J., Aspinwall, B., Parrott, W. A., et al. (2019). Genome-Scale Sequence Disruption Following Biolistic Transformation in Rice and Maize. Plant Cell 31 (2), 368-383. doi:10.1105/tpc.18.00613

Liu, W., Rudis, M. R., Cheplick, M. H., Millwood, R. J., Yang, J.-P., OndzighiAssoume, C. A., et al. (2020). Lipofection-mediated Genome Editing Using DNA-free Delivery of the Cas9/gRNA Ribonucleoprotein into Plant Cells. Plant Cel Rep. 39 (2), 245-257. doi:10.1007/s00299-01902488-w

Lowder, L. G., Zhang, D., Baltes, N. J., Paul, J. W., Tang, X., Zheng, X., et al. (2015). A CRISPR/Cas9 Toolbox for Multiplexed Plant Genome Editing and Transcriptional Regulation. Plant Physiol. 169 (2), 971-985. doi:10.1104/ pp. 15.00636

Lu, R. (2003). Virus-induced Gene Silencing in Plants. Methods 30 (4), 296-303. doi:10.1016/s1046-2023(03)00037-9

Ma, X., Zhang, X., Liu, H., and Li, Z. (2020). Highly Efficient DNA-free Plant Genome Editing Using Virally Delivered CRISPR-Cas9. Nat. Plants 6 (7), 773-779. doi:10.1038/s41477-020-0704-5

MacFarlane, S. A. (2008). "Tobravirus," in Encyclopedia of Virology. Editors B. W. J. Mahy and M. H. V. Van Regenmortel. Third Edition (Oxford: Academic Press), 72-76. doi:10.1016/b978-012374410-4.00515-x

Maher, M. F., Nasti, R. A., Vollbrecht, M., Starker, C. G., Clark, M. D., and Voytas, D. F. (2020). Plant Gene Editing through De Novo Induction of Meristems. Nat. Biotechnol. 38 (1), 84-89. doi:10.1038/s41587-019-0337-2

Malnoy, M., Viola, R., Jung, M.-H., Koo, O.-J., Kim, S., Kim, J.-S., et al. (2016). DNA-free Genetically Edited Grapevine and Apple Protoplast Using CRISPR/ Cas9 Ribonucleoproteins. Front. Plant Sci. 7, 1904. doi:10.3389/fpls.2016.01904

Mao, Y., Wang, M., Zhou, Y., Huang, B., Wu, Q., Zheng, Q., et al. (2021). Expanding the Target Range of Base Editing in Plants Without Loss of
Efficiency by Blocking RNA-silencing. Plant Biotechnol. J. 19 (12), 2389-2391. doi:10.1111/pbi.13712

Mao, Y., Botella, J. R., Liu, Y., and Zhu, J.-K. (2019). Gene Editing in Plants: Progress and Challenges. Natl. Sci. Rev. 6 (3), 421-437. doi:10.1093/nsr/nwz005

Mao, Y., Yang, X., Zhou, Y., Zhang, Z., Botella, J. R., and Zhu, J.-K. (2018). Manipulating Plant RNA-Silencing Pathways to Improve the Gene Editing Efficiency of CRISPR/Cas9 Systems. Genome Biol. 19 (1), 149. doi:10.1186/ s13059-018-1529-7

Mao, Y., Zhang, H., Xu, N., Zhang, B., Gou, F., and Zhu, J.-K. (2013). Application of the CRISPR-Cas System for Efficient Genome Engineering in Plants. Mol. Plant 6 (6), 2008-2011. doi:10.1093/mp/sst121

Marillonnet, S., Giritch, A., Gils, M., Kandzia, R., Klimyuk, V., and Gleba, Y. (2004). In Planta Engineering of Viral RNA Replicons: Efficient Assembly by Recombination of DNA Modules Delivered by Agrobacterium. Proc. Natl. Acad. Sci. 101 (18), 6852-6857. doi:10.1073/pnas.0400149101

Marillonnet, S., Thoeringer, C., Kandzia, R., Klimyuk, V., and Gleba, Y. (2005). Systemic Agrobacterium Tumefaciens-Mediated Transfection of Viral Replicons for Efficient Transient Expression in Plants. Nat. Biotechnol. 23 (6), 718-723. doi:10.1038/nbt1094

Martin-Ortigosa, S., Peterson, D. J., Valenstein, J. S., Lin, V. S.-Y., Trewyn, B. G., Lyznik, L. A., et al. (2013). Mesoporous Silica Nanoparticle-Mediated Intracellular Cre Protein Delivery for Maize Genome Editing via loxP Site Excision,. Plant Physiol. 164 (2), 537-547. doi:10.1104/pp.113.233650

Marton, I., Zuker, A., Shklarman, E., Zeevi, V., Tovkach, A., Roffe, S., et al. (2010). Nontransgenic Genome Modification in Plant Cells. Plant Physiol. 154 (3), 1079-1087. doi:10.1104/pp.110.164806

Mei, Y., Beernink, B. M., Ellison, E. E., Konečná, E., Neelakandan, A. K., Voytas, D. F., et al. (2019). Protein Expression and Gene Editing in Monocots Using Foxtail Mosaic Virus Vectors. Plant Direct 3 (11), e00181. doi:10.1002/pld3.181

Mortimer, C. L., Dugdale, B., and Dale, J. L. (2015). Updates in Inducible Transgene Expression Using Viral Vectors: from Transient to Stable Expression. Curr. Opin. Biotechnol. 32, 85-92. doi:10.1016/j.copbio.2014.11.009

Murovec, J., Guček, K., Bohanec, B., Avbelj, M., and Jerala, R. (2018). DNA-free Genome Editing of Brassica oleracea and B. Rapa Protoplasts Using CRISPRCas9 Ribonucleoprotein Complexes. Front. Plant Sci. 9, 1594. doi:10.3389/ fpls.2018.01594

Nadakuduti, S. S., and Enciso-Rodríguez, F. (2021). Advances in Genome Editing with CRISPR Systems and Transformation Technologies for Plant DNA Manipulation. Front. Plant Sci. 11 (2267), 637159. doi:10.3389/ fpls.2020.637159

Nasti, R. A., and Voytas, D. F. (2021). Attaining the Promise of Plant Gene Editing at Scale. Proc. Natl. Acad. Sci. USA 118 (22), e2004846117. doi:10.1073/ pnas. 2004846117

Nicolia, A., Andersson, M., Hofvander, P., Festa, G., and Cardi, T. (2021a). Tomato Protoplasts as Cell Target for Ribonucleoprotein (RNP)-mediated Multiplexed Genome Editing. Plant Cel Tiss Organ. Cult. 144 (2), 463-467. doi:10.1007/ s11240-020-01954-8

Nicolia, A., Fält, A.-S., Hofvander, P., and Andersson, M. (2021b). ProtoplastBased Method for Genome Editing in Tetraploid Potato. Methods Mol. Biol. 2264, 177-186. doi:10.1007/978-1-0716-1201-9_12

Pacher, M., and Puchta, H. (2017). From Classical Mutagenesis to Nuclease-Based Breeding - Directing Natural DNA Repair for a Natural End-Product. Plant J. 90 (4), 819-833. doi:10.1111/tpj.13469

Pan, C., Wu, X., Markel, K., Malzahn, A. A., Kundagrami, N., Sretenovic, S., et al. (2021). CRISPR-Act3.0 for Highly Efficient Multiplexed Gene Activation in Plants. Nat. Plants 7 (7), 942-953. doi:10.1038/s41477-021-00953-7

Park, S.-C., Park, S., Jeong, Y. J., Lee, S. B., Pyun, J. W., Kim, S., et al. (2019). DNAfree Mutagenesis of GIGANTEA in Brassica oleracea Var. Capitata Using CRISPR/Cas9 Ribonucleoprotein Complexes. Plant Biotechnol. Rep. 13 (5), 483-489. doi:10.1007/s11816-019-00585-6

Pausch, P., Al-Shayeb, B., Bisom-Rapp, E., Tsuchida, C. A., Li, Z., Cress, B. F., et al. (2020). CRISPR-Cas $\Phi$ from Huge Phages Is a Hypercompact Genome Editor. Science 369 (6501), 333-337. doi:10.1126/science.abb1400

Pogue, G., and Holzberg, S. (2012). "Transient Virus Expression Systems for Recombinant Protein Expression in Dicot- and Monocotyledonous Plants," in Plant Science (London, UK: InTech). 
Ranjan, S., Das Gupta, N., and Lichtfouse, E. (2017). Nanoscience in Food and Agriculture 5. Cham: Springer.

Sanzari, I., Leone, A., and Ambrosone, A. (2019). Nanotechnology in Plant Science: To Make a Long Story Short. Front. Bioeng. Biotechnol. 7, 120. doi:10.3389/ fbioe. 2019.00120

Scholthof, H. B., Scholthof, K.-B. G., and Jackson, A. O. (1996). Plant Virus Gene Vectors for Transient Expression of Foreign Proteins in Plants. Annu. Rev. Phytopathol. 34 (1), 299-323. doi:10.1146/annurev.phyto.34.1.299

Subburaj, S., Chung, S. J., Lee, C., Ryu, S.-M., Kim, D. H., Kim, J.-S., et al. (2016). Site-directed Mutagenesis in Petunia $\times$ Hybrida Protoplast System Using Direct Delivery of Purified Recombinant Cas9 Ribonucleoproteins. Plant Cel Rep. 35 (7), 1535-1544. doi:10.1007/s00299-016-1937-7

Sun, Y., Li, J., and Xia, L. (2016). Precise Genome Modification via Sequencespecific Nucleases-Mediated Gene Targeting for Crop Improvement. Front. Plant Sci. 7, 1928. doi:10.3389/fpls.2016.01928

Svitashev, S., Schwartz, C., Lenderts, B., Young, J. K., and Mark Cigan, A. (2016). Genome Editing in maize Directed by CRISPR-Cas9 Ribonucleoprotein Complexes. Nat. Commun. 7 (1), 13274. doi:10.1038/ ncomms 13274

Takamatsu, N., Ishikawa, M., Meshi, T., and Okada, Y. (1987). Expression of Bacterial Chloramphenicol Acetyltransferase Gene in Tobacco Plants Mediated by TMV-RNA. EMBO J. 6 (2), 307-311. doi:10.1002/j.14602075.1987.tb04755.x

Toda, E., Koiso, N., Takebayashi, A., Ichikawa, M., Kiba, T., Osakabe, K., et al. (2019). An Efficient DNA- and Selectable-marker-free Genome-Editing System Using Zygotes in rice. Nat. Plants 5 (4), 363-368. doi:10.1038/s41477-0190386-z

Torti, S., Schlesier, R., Thümmler, A., Bartels, D., Römer, P., Koch, B., et al. (2021). Transient Reprogramming of Crop Plants for Agronomic Performance. Nat. Plants 7 (2), 159-171. doi:10.1038/s41477-021-00851-y

Tsanova, T., Stefanova, L., Topalova, L., Atanasov, A., and Pantchev, I. (2021). DNA-free Gene Editing in Plants: a Brief Overview. Biotechnol. Biotechnol. Equip. 35 (1), 131-138. doi:10.1080/13102818.2020.1858159

Tsuda, M., Watanabe, K. N., and Ohsawa, R. (2019). Regulatory Status of GenomeEdited Organisms under the Japanese Cartagena Act. Front. Bioeng. Biotechnol. 7, 387. doi:10.3389/fbioe.2019.00387

Turnbull, C., Lillemo, M., and Hvoslef-Eide, T. A. K. (2021). Global Regulation of Genetically Modified Crops amid the Gene Edited Crop Boom - A Review. Front. Plant Sci. 12, 630396. doi:10.3389/fpls.2021.630396

Uranga, M., Aragonés, V., Selma, S., Vázquez-Vilar, M., Orzáez, D., and Daròs, J. A. (2021a). Efficient Cas9 Multiplex Editing Using Unspaced sgRNA Arrays Engineering in a Potato Virus X Vector. Plant J. 106 (2), 555-565. doi:10.1111/tpj.15164

Uranga, M., Vazquez-Vilar, M., Orzáez, D., and Daròs, J.-A. (2021b). CRISPRCas12a Genome Editing at the Whole-Plant Level Using Two Compatible RNA Virus Vectors. CRISPR J. 4 (5), 761-769. doi:10.1089/crispr.2021.0049

van Kregten, M., de Pater, S., Romeijn, R., van Schendel, R., Hooykaas, P. J. J., and Tijsterman, M. (2016). T-DNA Integration in Plants Results from Polymerase$\theta$-Mediated DNA Repair. Nat. Plants 2 (11), 16164. doi:10.1038/ nplants.2016.164

Vejlupkova, Z., Warman, C., Sharma, R., Scheller, H. V., Mortimer, J. C., and Fowler, J. E. (2020). No Evidence for Transient Transformation via Pollen Magnetofection in Several Monocot Species. Nat. Plants 6 (11), 1323-1324. doi:10.1038/s41477-020-00798-6

Voytas, D. F., and Gao, C. (2014). Precision Genome Engineering and Agriculture: Opportunities and Regulatory Challenges. Plos Biol. 12 (6), e1001877. doi:10.1371/journal.pbio.1001877

Walker, P. J., Firth, C., Widen, S. G., Blasdell, K. R., Guzman, H., Wood, T. G., et al. (2015). Evolution of Genome Size and Complexity in the Rhabdoviridae. Plos Pathog. 11 (2), e1004664. doi:10.1371/journal.ppat.1004664

Wang, J. W., Cunningham, F. J., Goh, N. S., Boozarpour, N. N., Pham, M., and Landry, M. P. (2021). Nanoparticles for Protein Delivery in Planta. Curr. Opin. Plant Biol. 60, 102052. doi:10.1016/j.pbi.2021.102052

Wang, M., Lu, Y., Botella, J. R., Mao, Y., Hua, K., and Zhu, J.-k. (2017). Gene Targeting by Homology-Directed Repair in rice Using a Geminivirus-Based CRISPR/Cas9 System. Mol. Plant 10 (7), 1007-1010. doi:10.1016/ j.molp.2017.03.002
Wang, T., Zhang, H., and Zhu, H. (2019). CRISPR Technology Is Revolutionizing the Improvement of Tomato and Other Fruit Crops. Hortic. Res. 6 (1), 77. doi:10.1038/s41438-019-0159-x

Wolter, F., and Puchta, H. (2017). Knocking Out Consumer Concerns and Regulator's Rules: Efficient Use of CRISPR/Cas Ribonucleoprotein Complexes for Genome Editing in Cereals. Genome Biol. 18 (1), 43. doi:10.1186/s13059-017-1179-1

Woo, J. W., Kim, J., Kwon, S. I., Corvalán, C., Cho, S. W., Kim, H., et al. (2015). DNA-free Genome Editing in Plants with Preassembled CRISPR-Cas9 Ribonucleoproteins. Nat. Biotechnol. 33 (11), 1162-1164. doi:10.1038/nbt.3389

Wu, S., Zhu, H., Liu, J., Yang, Q., Shao, X., Bi, F., et al. (2020). Establishment of a PEG-Mediated Protoplast Transformation System Based on DNA and CRISPR/Cas9 Ribonucleoprotein Complexes for Banana. BMC Plant Biol. 20 (1), 425. doi:10.1186/s12870-020-02609-8

Xu, X., Chemparathy, A., Zeng, L., Kempton, H. R., Shang, S., Nakamura, M., et al. (2021). Engineered Miniature CRISPR-Cas System for Mammalian Genome Regulation and Editing. Mol. Cel 81 (20), 4333-4345. doi:10.1016/ j.molcel.2021.08.008

Yang, B. (2020). Grand Challenges in Genome Editing in Plants. Front. Genome Ed. 2, 2. doi:10.3389/fgeed.2020.00002

Yin, K., Han, T., Liu, G., Chen, T., Wang, Y., Yu, A. Y. L., et al. (2015). A Geminivirus-Based Guide RNA Delivery System for CRISPR/Cas9 Mediated Plant Genome Editing. Sci. Rep. 5 (1), 14926. doi:10.1038/srep14926

Yu, J., Tu, L., Subburaj, S., Bae, S., and Lee, G.-J. (2021). Simultaneous Targeting of Duplicated Genes in Petunia Protoplasts for Flower Color Modification via CRISPR-Cas9 Ribonucleoproteins. Plant Cel Rep. 40 (6), 1037-1045. doi:10.1007/s00299-020-02593-1

Yue, J.-J., Yuan, J.-L., Wu, F.-H., Yuan, Y.-H., Cheng, Q.-W., Hsu, C.-T., et al. (2021). Protoplasts: From Isolation to CRISPR/Cas Genome Editing Application. Front. Genome Ed. 3 (19), 717017. doi:10.3389/ fgeed.2021.717017

Zhan, X., Lu, Y., Zhu, J. K., and Botella, J. R. (2021). Genome Editing for Plant Research and Crop Improvement. J. Integr. Plant Biol. 63 (1), 3-33. doi:10.1111/ jipb.13063

Zhang, X., Kang, L., Zhang, Q., Meng, Q., Pan, Y., Yu, Z., et al. (2020). An RNAi Suppressor Activates in Planta Virus-Mediated Gene Editing. Funct. Integr. Genomics 20 (4), 471-477. doi:10.1007/s10142-019-00730-y

Zhang, Y., Massel, K., Godwin, I. D., and Gao, C. (2018). Applications and Potential of Genome Editing in Crop Improvement. Genome Biol. 19 (1), 210. doi:10.1186/s13059-018-1586-y

Zhang, Y., Liang, Z., Zong, Y., Wang, Y., Liu, J., Chen, K., et al. (2016). Efficient and Transgene-free Genome Editing in Wheat Through Transient Expression of CRISPR/Cas9 DNA or RNA. Nat. Commun. 7 (1), 12617. doi:10.1038/ ncomms 12617

Zhao, X., Meng, Z., Wang, Y., Chen, W., Sun, C., Cui, B., et al. (2017). Pollen Magnetofection for Genetic Modification with Magnetic Nanoparticles as Gene Carriers. Nat. Plants 3 (12), 956-964. doi:10.1038/s41477-017-0063-Z

Zong, Y., Wang, Y., Li, C., Zhang, R., Chen, K., Ran, Y., et al. (2017). Precise Base Editing in rice, Wheat and maize with a Cas9-Cytidine Deaminase Fusion. Nat. Biotechnol. 35 (5), 438-440. doi:10.1038/nbt.3811

Conflict of Interest: The authors declare that the research was conducted in the absence of any commercial or financial relationships that could be construed as a potential conflict of interest.

Publisher's Note: All claims expressed in this article are solely those of the authors and do not necessarily represent those of their affiliated organizations, or those of the publisher, the editors and the reviewers. Any product that may be evaluated in this article, or claim that may be made by its manufacturer, is not guaranteed or endorsed by the publisher.

Copyright $\odot 2021$ Gong, Cheng and Botella. This is an open-access article distributed under the terms of the Creative Commons Attribution License (CC BY). The use, distribution or reproduction in other forums is permitted, provided the original author(s) and the copyright owner(s) are credited and that the original publication in this journal is cited, in accordance with accepted academic practice. No use, distribution or reproduction is permitted which does not comply with these terms. 